Article

\title{
Nitric Oxide Synthase Is Involved in Follicular Development via the PI3K/AKT/FoxO3a Pathway in Neonatal and Immature Rats
}

\author{
Junrong Li ${ }^{1, * \mathbb{C}}$, Wei Zhang ${ }^{2}$, Shanli Zhu ${ }^{1}$ and Fangxiong Shi ${ }^{2} \mathbb{C}$ \\ 1 College of Agriculture and Bio-Engineering, Jinhua Polytechnic, Jinhua 321017, China; 20191040@jhc.edu.cn \\ 2 College of Animal Science and Technology, Nanjing Agricultural University, Nanjing 210095, China; \\ yuntaishan2003@aliyun.com (W.Z.); fxshi@njau.edu.cn (F.S.) \\ * Correspondence: jrli@jhc.edu.cn; Tel.: +86-135-8860-6686
}

Received: 22 January 2020; Accepted: 4 February 2020; Published: 5 February 2020

\begin{abstract}
It is assumed that nitric oxide synthase and nitric oxide are involved in the regulation of female reproduction. This study aimed to assess the roles of nitric oxide synthase (NOS) in follicular development. The endothelial NOS (eNOS) inhibitor L-NAME, inducible NOS (iNOS) inhibitor S-Methylisothiourea (SMT) and NOS substrate L-arginine (L-Arg) were used in the NOS inhibition models in vivo. Neonatal female rats were treated with phosphate buffer saline (PBS, control), L-NAME (L-NG-Nitroarginine Methyl Ester, $40 \mathrm{mg} / \mathrm{kg}$ ), SMT (S-Methylisothiourea, $10 \mathrm{mg} / \mathrm{kg}$ ), L-NAME + SMT, or L-Arg (L-arginine, $50 \mathrm{mg} / \mathrm{kg}$ ) via subcutaneous (SC) injection on a daily basis for 19 consecutive days, with the samples being collected on specific postnatal days (PD5, PD10, and PD19). The results indicated that the number of antral follicles, the activity of total-NOS, iNOS, neuronal NOS (nNOS), and eNOS, and the content of NO in the ovary were significantly $(p<0.05)$ increased in the L-Arg group at PD19, while those in L + S group were significantly $(p<0.05)$ decreased. Meanwhile, the ovarian expression in the L-Arg group in terms of p-AKT, p-FoxO3a, and LC3-II on PD19 were significantly $(p<0.05)$ upregulated, while the expressions of PTEN and cleaved Caspase-3 were $(p<0.05)$ downregulated as a result of NOS/NO generation, respectively. Therefore, the results suggest that NOS is possibly involved in the maturation of follicular development to puberty via the PI3K/AKT/FoxO3a pathway, through follicular autophagia and apoptosis mechanisms.
\end{abstract}

Keywords: nitric oxide synthase; PTEN; AKT; FoxO3a; follicular development

\section{Introduction}

Nitric oxide (NO) is a key gaseous signaling molecule that functions as a biological mediator and is produced by mammalian cells [1-3]. NO can be generated by the enzyme nitric oxide synthase (NOS) with three different isoforms, including neuronal NOS (nNOS), inducible NOS (iNOS), and endothelial NOS (eNOS), formed from L-arginine (L-Arg) in the presence of nicotinamide-adenine-dinucleotide phosphate (NADPH) as a substrate and co-substrate, respectively [4]. Calcium/calmodulin dependent nNOS and eNOS temporarily produce a small amount of NO, whereas the synthesis of NO over a long period is generated by iNOS, which is regulated by several cytokines and hormones [5]. NO and NOS are possibly involved in the regulation of female rat reproduction [6,7], such as in the follicular development in rats [8], and may also have a role in the reproduction of sheep [9], oocyte competence in pigs and cattle [10], luteal regression in sheep [5,11], ovarian steroidogenesis in rats [12], vitellogenesis in fish [13], and advanced onset of puberty in rats [14]. Females with polycystic ovary syndrome (PCOS) have a lowered level of NO due to reduced iNOS/eNOS expression and arginine bioavailability [15]. The estrus cycle is prolonged in a female mouse model after the knockout of eNOS 
genes $[16,17]$, and a role for eNOS has been suggested in the selection of nonovulatory dominant follicles in bovines [18] and in the ovulatory process in ewes [11]. NO is produced by iNOS only in immature follicles, which has a cytostatic factor in the earlier stages of rat follicular development [19]. Moreover, the ovulation rate and implantation loss are increased by disruption of eNOS and iNOS [16]. Knocking out the three isoenzymes of NOS in mice leads to a significant decline of the fertility rate, as well as the occurrence of various cardiovascular diseases [20].

The PI3K/AKT pathway is a key regulator of cell proliferation, growth, and survival [21,22]. The FoxO transcription factors, also called the forkhead transcription factors, are a subfamily including FOXO3A (FKHRL1), FOXO1A (FKHR), FOXO6, and FOXO4 (AFX), with pivotal roles in the PTEN/PI3K/AKT pathway [23]. FoxO3a has been proposed to be the key transcription factor in the PI3K/PTEN-mediated maintenance of primordial follicle reserves [24]. The PI3K pathway regulates the activation of primordial follicles via transcription factor FoxO3 [25-27], and it has been reported that PI3K inhibitor decreases the levels of phosphorylated FoxO3a (p-FoxO3a) while increasing the levels of nuclear FoxO3a [28]. The PI3K/AKT/FoxO3a pathway is involved in the regulation of various physiological processes via NO or NOS, guaranteeing an improved follicular microenvironment for developing oocytes and inhibiting granulosa cell apoptosis [29,30]. During the migration of endothelial cells, peroxisome proliferator-activated receptor coactivator $1 \alpha(\mathrm{PGC}-1 \alpha)$ is downregulated by NO via the activation of the PI3K/protein kinase B (Akt protein) pathway and FoxO3a protein [31]. The balance of the PI3K signaling pathway is pivotal to maintain the growth and survival of the primordial follicle pool [32]; a rodent model revealed that the PI3K/AKT pathway mediated oocyte apoptosis and FoxO3a plays an important role in early follicular development [29]. Furthermore, FoxO3a was found to maintain the PTEN-PI3K-AKT-FoxO3a pathway, enabling faster follicle growth [33]. Previous researchers have found that locally produced NO and the NOS/sGC pathway might be involved in the maturation of the follicles [34,35]. However, the mechanism of the PI3K/AKT/FoxO3a pathway via $\mathrm{NO} / \mathrm{NOS}$ participation in the follicular development of neonatal and immature animals has not been reported yet, and requires further investigation.

Previous studies on the mechanisms of NOS inhibitor injection either in vitro or in vivo, including L-NG-Nitroarginine Methyl Ester (L-NAME) and S-Methylisothiourea (SMT) as eNOS-selective (non-selective at high level), and iNOS-selective inhibitors, respectively [36-39], have proposed that L-NAME would significantly reduce cyclic guanosine monophosphate (cGMP) production in follicles in vitro [40], impair folliculogenesis, and delay ovarian follicular development [41]. In addition, the offspring of pregnant rats which underwent in utero exposure to L-NAME exhibit decreased neonatal weight, postnatal growth, and fertility [42]. Meanwhile, NOS substrate L-Arg is widely used to produce NO [43-45]. Finally, in recent decades, an increasing number of studies have concentrated on the effects of NOS on the reproductive system of female rats. So far, there has been no study to evaluate the effects of NOS on follicular development in neonatal and immature rats. Therefore, we herein adopted subcutaneous administration of the L-NAME, SMT, or L-Arg to generate a NOS inhibition model in rats, and clarify the effects of NOS on follicular development via the regulating mechanisms of the NO/cGMP and PI3K pathways.

\section{Materials and Methods}

\subsection{Experimental Design and Ethics Statement}

Ten male and ten female mature Sprague-Dawley rats were selected for the experiment and kept at a room temperature of $22 \pm 1{ }^{\circ} \mathrm{C}$ and relative humidity of $30-40 \%$. Females and males were randomly matched and mated (1:1), after which the female rats gave birth to neonatal female rats. The individuals (body weight $4-5 \mathrm{~g}$ ) from each litter were randomly assigned to five groups $(n=5)$. The first day of birth was numbered as postnatal day 1 (PD1). The neonatal female rats from the five groups were subcutaneously injected with $50 \mu \mathrm{L}$ phosphate buffer saline (PBS, control), a solution of L-NG-Nitroarginine Methyl Ester (L-NAME, $40 \mathrm{mg} / \mathrm{kg}$ ), S-Methylisothiourea (SMT, $10 \mathrm{mg} / \mathrm{kg}$ ), 
L-NAME plus SMT $(\mathrm{L}+\mathrm{S}$ ), or L-Arginine (L-Arg, $50 \mathrm{mg} / \mathrm{kg}$ ) daily in the morning from PD1 for 19 consecutive days. The animals were euthanized by $\mathrm{CO}_{2}$ anesthesia on PD5, PD10, or PD19 (12 $\mathrm{h}$ after injection), and the ovaries collected under stereomicroscopy. The right-side ovary was fixed in $4 \%$ paraformaldehyde for hematoxylin-eosin staining (HE), while the left-side samples were measured for NOS activity and NO concentration before they were stored at $-80^{\circ} \mathrm{C}$ for Western blotting analysis (WB). The experiment procedures conformed to the guidelines for the care and use of experimental animals issued by the Animal Ethical and Welfare Committee of Jinhua Polytechnic (approval number: 20170609-01), China.

\subsection{Histological and Morphological Examination}

The samples were fixed for $24 \mathrm{~h}$ and then embedded in paraffin wax and sectioned serially at $4 \mu \mathrm{m}$. The HE tissues were stained with hematoxylin and eosin (Nanjing Jiancheng Bioengineering Institute, Nanjing, China). The follicles were counted by evaluating six slices per sample (randomly 10-15 slices interval with different number of follicles), and were then divided into unassembled follicles, primordial follicles, primary follicles, secondary follicles, and tertiary follicles (antral follicles) [46]. Each primordial follicle consisted of a layer of flat follicular cells and an immature oocyte. After the follicular cells outside the oocyte turned from a flat shape into a cuboid one, a primary follicle was formed. A secondary follicle was formed with the gradual increase of granulosa cell layers [17]. At the stage of tertiary follicles, the granulosa cells differentiated into multiple layers and formed cavities; these are also called antral follicles.

\subsection{Measurement of NOS Activity and NO Concentration}

The ovaries were weighed and homogenized in iced saline (tissue weight/lysis buffer weight 1:10 suspension), then centrifuged for $10 \mathrm{~min}(2500 \mathrm{r})$ at $4{ }^{\circ} \mathrm{C}$. The activities of total NOS, iNOS, and cNOS $(\mathrm{eNOS}+\mathrm{nNOS})$ were measured with a commercial NOS-typed assay kit (the inter- and intra-coefficient of variation of assays were respectively $2.10 \%$ and $6.01 \%$, detection limit: $0.2-81.9 \mathrm{U} / \mathrm{mL}$ ) (Nanjing Jiancheng Bioengineering Institute, Nanjing, China). The ovarian protein homogenates $(800 \mu \mathrm{g} / \mathrm{mL})$ were treated with nNOS inhibitor spermidine trihydrochloride $\left(120 \mu \mathrm{mol} / \mathrm{mL}, \mathrm{C}_{7} \mathrm{H}_{19} \mathrm{~N}_{3} \cdot 3 \mathrm{HCl}\right)$ to further address the eNOS activity [34], and the optical density was measured at $530 \mathrm{~nm}$ by an ELISA reader $(n=5)$ (BioTek Instruments, Inc., Winooski, VT, USA) based on the release of lactate NO generated by a 5 -electron oxidation of terminal guanidinium nitrogen on L-arginine [47].

\subsection{Western Blotting}

The samples stored at $-80{ }^{\circ} \mathrm{C}$ were homogenized in radio-immunoprecipitation assay (RIPA) buffer with $10 \mathrm{mM}$ PMSF. An equal amount of protein lysate $(50 \mu \mathrm{g})$ was separated by $12 \%(\mathrm{w} / \mathrm{v})$ sodium dodecyl sulfate polyacrylamide gel electrophoresis (SDS-PAGE, Sangon Biotech, Shanghai, China), and electro-transferred onto polyvinylidene fluoride (PVDF) membranes (Millipore, Burlington, MA, USA). The membranes were blocked with $3 \%$ BSA (BBI, Shanghai, China) for $2 \mathrm{~h}$ at $25^{\circ} \mathrm{C}$, and incubated with primary antibodies (diluted in PBS) of $\beta$-tubulin (1:5000, ab6046, Abcam, Cambridge, UK), PTEN (1:1000, sc-7974, Santa Cruz Biotechnology, Inc., Santa Cruz, CA, USA), P-AKT (1:500, ab207452, Abcam, Cambridge, UK), AKT (1:1000, 9272, Cell Signaling, Danvers, MA, USA), p-FoxO3a (1:1000, 9464, Cell Signaling, Danvers, MA, USA), FoxO3a (1:1000, ab47285, Abcam, Cambridge, UK), cleaved Caspase-3 (1:2000, 9661, Cell Signaling, Danvers, MA, USA), and LC3-II (1:1000, 3868, Cell Signaling, Danvers, MA, USA) for $16 \mathrm{~h}$ at $4{ }^{\circ} \mathrm{C}$. The incubated membranes were washed with fresh TBST (Tris-Buffered Saline Tween) buffer and incubated with HRP (Horseradish Peroxidase)-conjugated secondary donkey anti-goat IgG antibody (1:3000, A0181, Beyotime, Haimen, Jiangsu, China), followed by goat anti-rabbit IgG antibody (1:3000, SN134, Sunshine, China) at room temperature for $2 \mathrm{~h}$, respectively. The bands were washed in TBST buffer (five times) and detected with a Pierce ECL WB Substrate (Thermo Scientific, Waltham, MA, USA), and visualized by a Luminescent Image Analyzer LAS4000 (Fuji Film, Tokio, Japan). The signal intensity was plotted as the ratio of the target protein to $\beta$-tubulin. 


\subsection{Statistical Analysis}

All numerical results are expressed as mean \pm standard error of the mean (mean \pm SEM). Data were analyzed by one-way analysis of variance (ANOVA) followed by Tukey's multiple comparison test using SPSS version 13.0, with $p<0.05$ being considered as significant statistical difference.

\section{Results}

\subsection{Follicular Development}

Compared with the control group, the percent of primordial follicles in group L-Arg (Figure 1A) was significantly $(p<0.05)$ decreased on PD5, while primary follicles were significantly $(p<0.05)$ increased. The percentage of primary follicle in the $\mathrm{L}+\mathrm{S}$ group was significantly $(p<0.05)$ higher than in the control group and L-Arg on PD10, and the percentage of secondary follicles in the L-Arg group was significantly $(p<0.05)$ higher than in the control group and $\mathrm{L}+\mathrm{S}$ (Figure 1B). However, the percentage of secondary follicles in the L-Arg and L $+S$ groups was significantly $(p<0.05)$ decreased on PD19, and the percentage of antral follicles was significantly increased in the L-Arg group and significantly decreased in the $\mathrm{L}+\mathrm{S}$ group, respectively $(p<0.05$, Figure $1 \mathrm{C})$.
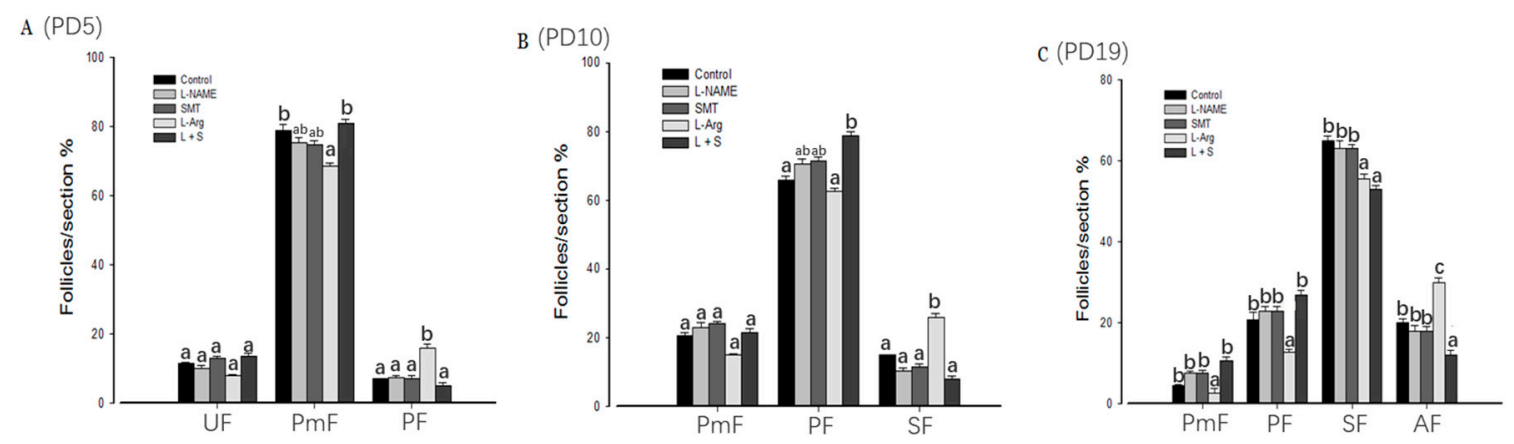

Figure 1. Effect of nitric oxide synthase (NOS) inhibitors and substrate on follicular development in neonatal and immature rats. Animals in the control, L-NG-Nitroarginine Methyl Ester (L-NAME), S-Methylisothiourea (SMT), L-arginine (L-Arg), or L + S (L-NAME plus SMT) groups were subcutaneously hypodermically injected with phosphate buffer saline (PBS), L-NAME (40 mg/kg), SMT (10 mg/kg), L-NG-Nitroarginine Methyl Ester $(40 \mathrm{mg} / \mathrm{kg})$ and S-Methylisothiourea $(10 \mathrm{mg} / \mathrm{kg})$, or L-arginine (50 mg/kg) for five (PD5, A), 10 (PD10, B), or 19 days (PD19, C) from the first day of birth (PD1). UF, unassembled follicle; PmF, primordial follicle; $\mathrm{PF}$, primary follicle; $\mathrm{SF}$, secondary follicle; $\mathrm{AF}$, antral follicle. Bars with different letters denote significant differences $(p<0.05)$.

\subsection{Ovarian NOS Activity and NO Content}

The ovarian activity of total-NOS, iNOS, nNOS, and eNOS, and the content of NO, showed no significant $(p>0.05)$ differences among the control group, L-NAME and SMT (Figure 2A-E) on PD5, PD10, and PD19. Compared with the control group, the ovarian activity of total-NOS, iNOS, nNOS, and eNOS, and the content of NO, in the $\mathrm{L}+\mathrm{S}$ group were significantly lower on PD5, PD10, and PD19 $(p<0.05$, Figure 2A-E). The ovarian activity level of total-NOS, iNOS, and eNOS and the content of NO, in the L-Arg group were significantly elevated on PD10 $(p<0.05$, Figure 2A,B,D,E), and the ovarian activity levels of total-NOS, iNOS, nNOS, and eNOS, and the content of NO, in the L-Arg group were significantly elevated on PD19 ( $p<0.05$, Figure 2A-E). 

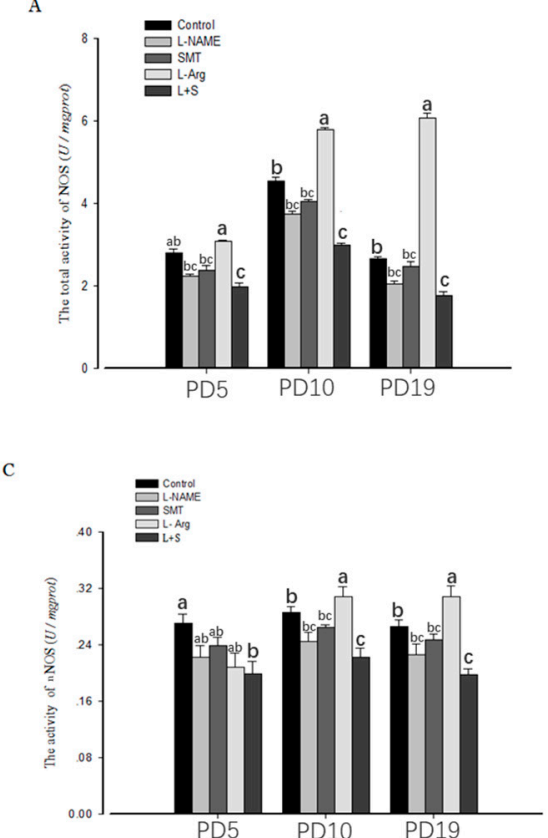
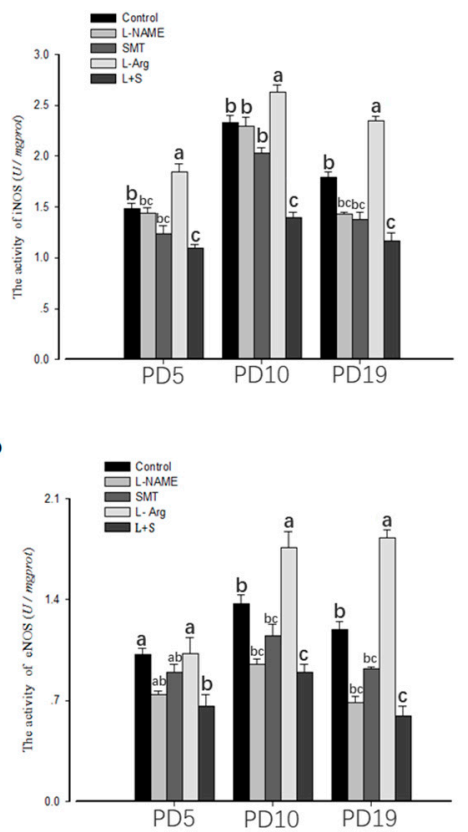

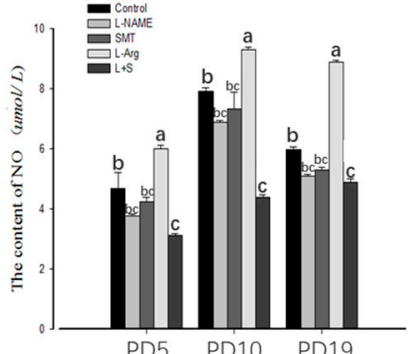

Figure 2. Effect of NOS inhibitors and substrate on ovarian NOS (total NOS, A; iNOS, B; nNOS, C; eNOS, D) activity and NO concentration (E) in neonatal and immature rats. Animals in the control, L-NAME, SMT, L-Arg or L + S (L-NAME plus SMT) groups were subcutaneously hypodermically injected with PBS, L-NG-Nitroarginine Methyl Ester $(40 \mathrm{mg} / \mathrm{kg})$, S-Methylisothiourea (10 mg/kg), or L-NG-Nitroarginine Methyl Ester $(40 \mathrm{mg} / \mathrm{kg}$ ) and S-Methylisothiourea $(10 \mathrm{mg} / \mathrm{kg})$, L-arginine (50 mg/kg) for five (PD5), 10 (PD10), or 19 days (PD19) from the first day of birth (PD1). Bars with different letters denote significant differences $(p<0.05)$.

\subsection{Ovarian Expression of PTEN, p-AKT, AKT, p-FoxO3a and FoxO3a}

The injection of L-NAME or SMT resulted no significant difference of the ovarian expression of PTEN, p-AKT, AKT, p-FoxO3a, and FoxO3a on PD5, PD10, and PD19 in comparison with the control ( $p>0.05$, Figures 3-5). Furthermore, no significant differences were observed in the ovarian expressions of AKT and FoxO3a on PD5, PD10, and PD10 among all groups ( $p>0.05$, Figure 3C,E, Figure 4C,E and Figure 5C,E).

Compared with the control group, the injection of L-Arg resulted in no significant difference in the ovarian expression of PTEN, p-AKT, and p-FoxO3a on PD5 ( $p>0.05$, Figure 3A,B,D). The ovarian expression of p-AKT and p-FoxO3a in the L-Arg group was significantly upregulated at PD10 $(p<0.05$, Figure 4B,D), and the ovarian expression of PTEN in the L-Arg group was significantly downregulated on PD19, with significant upregulation of the ovarian expression of p-AKT and p-FoxO3a $(p<0.05$, Figure 5A,B,D). Additionally, the rats in the L-Arg group showed significantly lower expression of PTEN and significantly higher expression of p-AKT and p-FoxO3a on PD5, PD10, and PD19 in comparison with animals injected with L-NAME plus SMT $(p<0.05$, Figure 3A,B,D, Figure 4A,B,D and Figure 5A,B,D).

Compared with the control group, the ovarian expression of $\mathrm{p}-\mathrm{AKT}$ in the $\mathrm{L}+\mathrm{S}$ group was significantly downregulated on PD5 ( $p<0.05$, Figure 3B), and the ovarian expression of PTEN in the L $+\mathrm{S}$ group was significantly upregulated on PD10, with the significant downregulation of the ovarian expression of p-FoxO3a $(p<0.05$, Figure $4 \mathrm{~A}, \mathrm{D})$. The ovarian expression of PTEN in the $\mathrm{L}+\mathrm{S}$ group was significantly upregulated on PD19, with significant downregulation of the ovarian expression of p-AKT and p-FoxO3a $(p<0.05$, Figure 5A,B,D). 


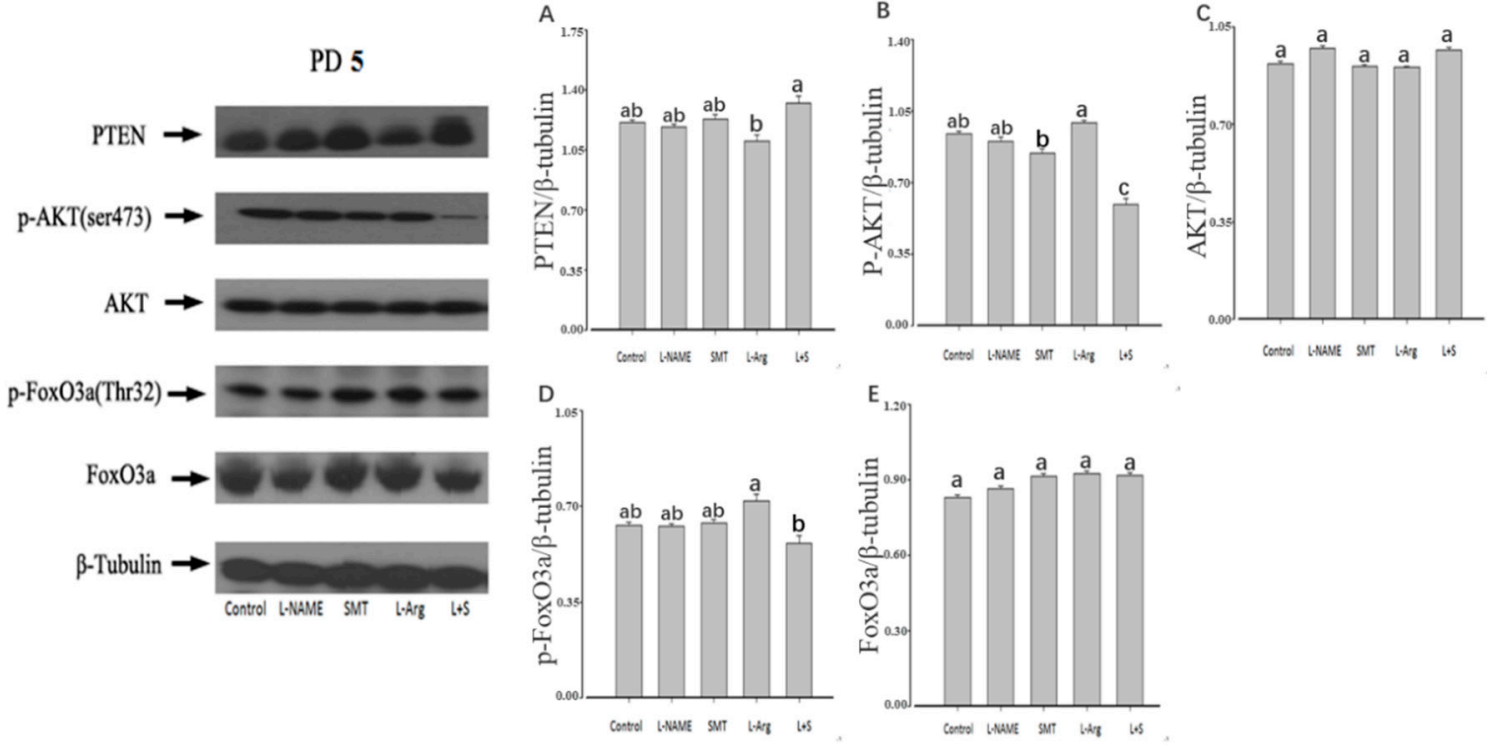

Figure 3. Effect of NOS inhibitors and substrate on ovarian expression of PTEN (A), p-AKT (B), AKT (C), p-FoxO3a (D), and FoxO3a (E) in neonatal rats. Animals in the control, L-NAME, SMT, L-Arg, or L + S (L-NAME plus SMT) groups were subcutaneously hypodermically injected with PBS, L-NG-Nitroarginine Methyl Ester (40 mg/kg), S-Methylisothiourea (10 mg/kg), L-NG-Nitroarginine Methyl Ester (40 mg/kg) and S-Methylisothiourea (10 mg/kg), or L-arginine (50 mg/kg) for five days (PD5) from the first day of birth (PD1). $\beta$-tubulin was used as an internal control, wherein the signal intensity was plotted as the ratio of target protein to $\beta$-tubulin. Bars with different letters denote significant differences $(p<0.05)$.
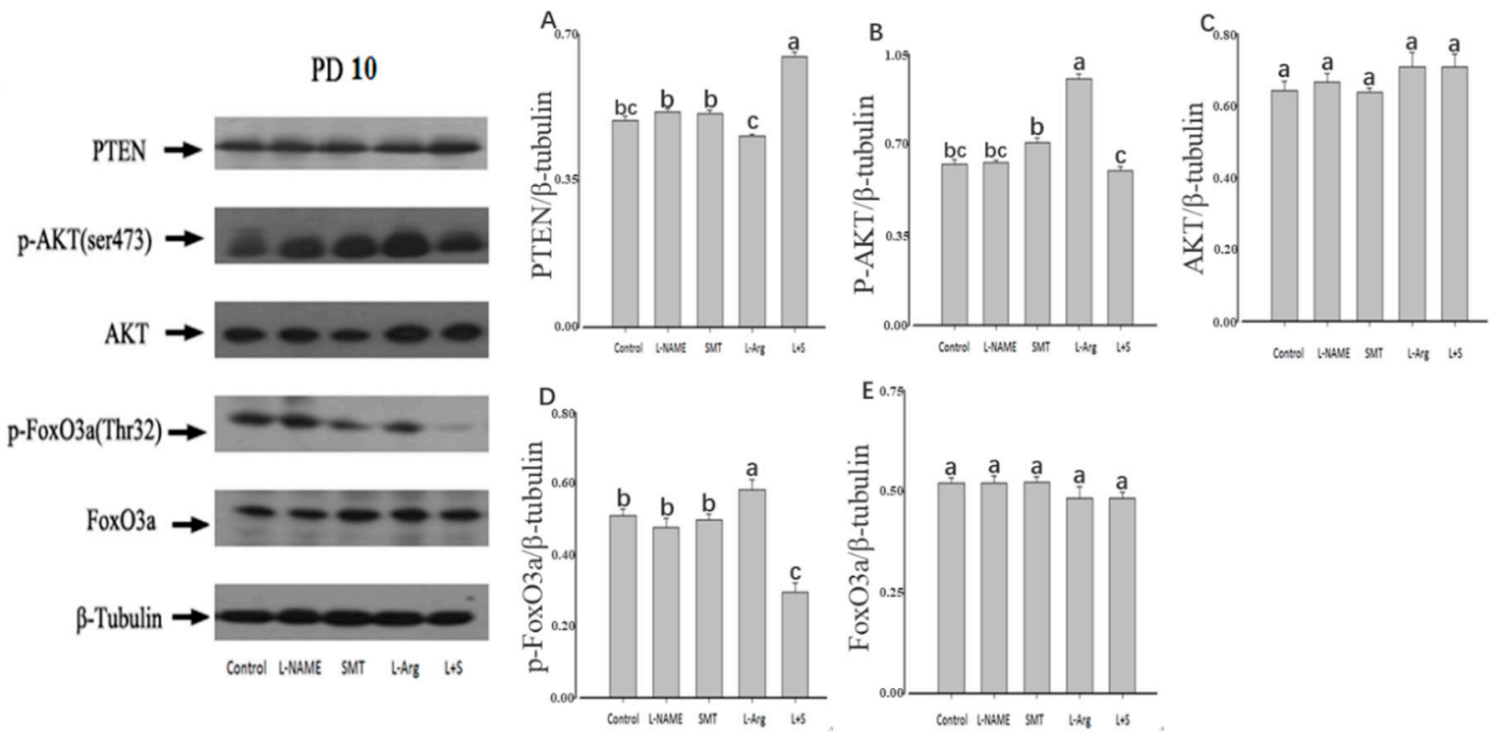

Figure 4. Effect of NOS inhibitors and substrate on ovarian expression of PTEN (A), p-AKT (B), AKT (C), p-FoxO3a (D), and FoxO3a (E) in immature rats. Animals in the control, L-NAME, SMT, L-Arg, or L + S (L-NAME plus SMT) groups were subcutaneously hypodermically injected with PBS, L-NG-Nitroarginine Methyl Ester (40 mg/kg), S-Methylisothiourea (10 mg/kg), L-NG-Nitroarginine Methyl Ester (40 mg/kg) and S-Methylisothiourea $(10 \mathrm{mg} / \mathrm{kg})$, or L-arginine $(50 \mathrm{mg} / \mathrm{kg}$ ) for 10 days (PD10) from the first day of birth (PD1). As an internal control, $\beta$-tubulin was used, wherein the signal intensity was plotted as the ratio of target protein to $\beta$-tubulin. Bars with different letters denote significant differences $(p<0.05)$. 


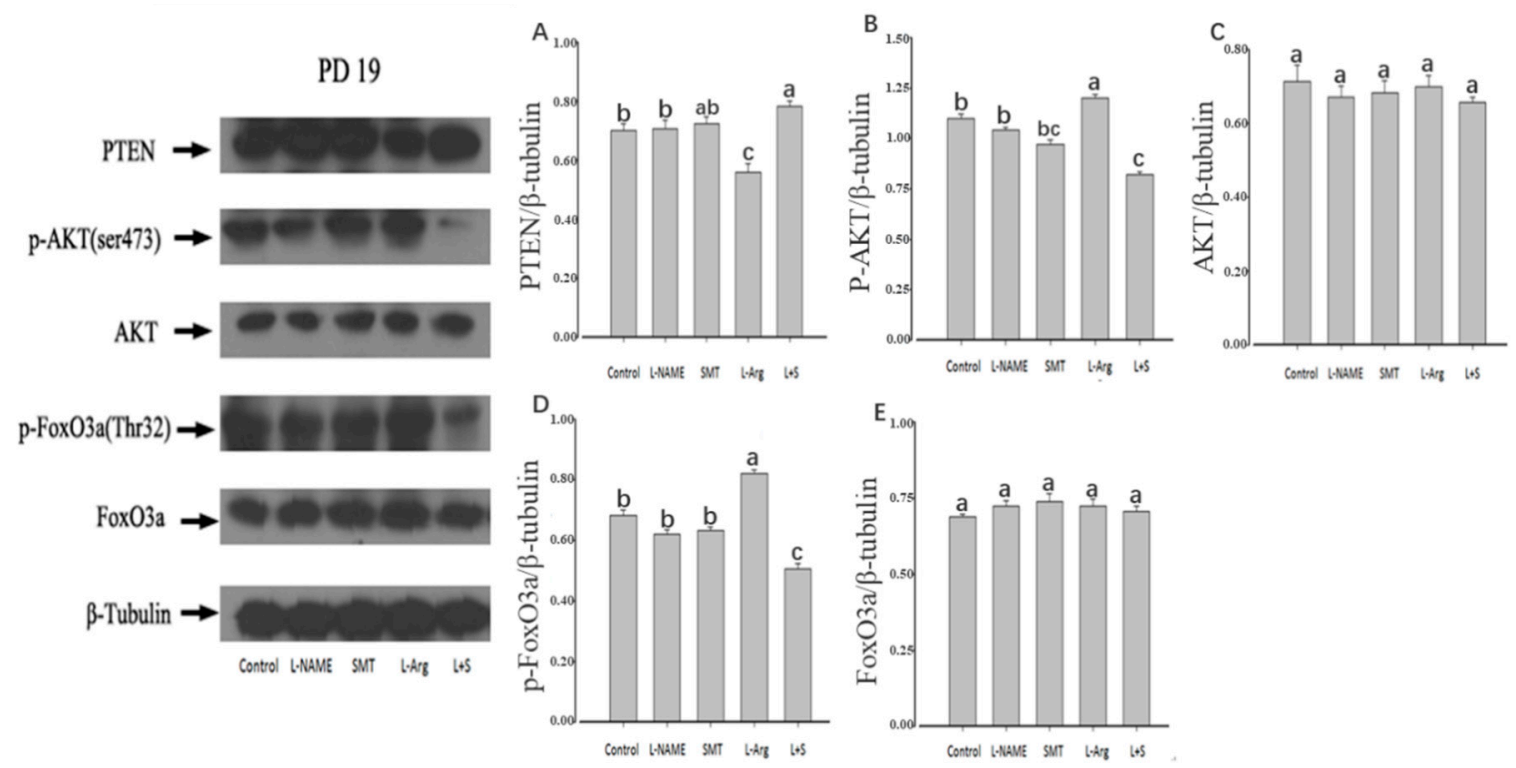

Figure 5. Effect of NOS inhibitors and substrate on ovarian expression of PTEN (A), p-AKT (B), AKT (C), p-FoxO3a (D), and FoxO3a (E) in immature rats. Animals in the control, L-NAME, SMT, L-Arg, or L + S (L-NAME plus SMT) groups were subcutaneously hypodermically injected with PBS, L-NG-Nitroarginine Methyl Ester (40 mg/kg), S-Methylisothiourea (10 mg/kg), L-NG-Nitroarginine Methyl Ester (40 mg/kg) and S-Methylisothiourea $(10 \mathrm{mg} / \mathrm{kg})$, or L-arginine (50 mg/kg) for 19 days (PD19) from the first day of birth (PD1). As an internal control, $\beta$-tubulin was used, wherein the signal intensity was plotted as the ratio of target protein to $\beta$-tubulin. Bars with different letters denote significant differences $(p<0.05)$.

\subsection{Ovarian Expression of LC3-II and Cleaved-Caspase-3}

This study showed that there were no significant differences in the expression patterns of LC3-II and cleaved Caspase-3 among the control, L-NAME, and SMT groups on PD5, PD10, or PD19 $(p>0.05$, Figure 6A-F). Compared with the control group, the ovarian expression of LC3-II in the L-Arg group was significantly upregulated on PD5, PD10, and PD19 ( $p<0.05$, Figure 6A,C,E), while the ovarian expression of cleaved Caspase-3 was significantly downregulated on PD10 and PD19 $(p<0.05$, Figure 6D,F). In contrast, the ovarian expression of LC3-II in the L + S group was significantly downregulated on PD5 and PD19 ( $p<0.05$, Figure 6A,E), while the ovarian expression of cleaved Caspase-3 was significantly upregulated on PD5, PD10, and PD19 $(p<0.05$, Figure 6B,D,F). 

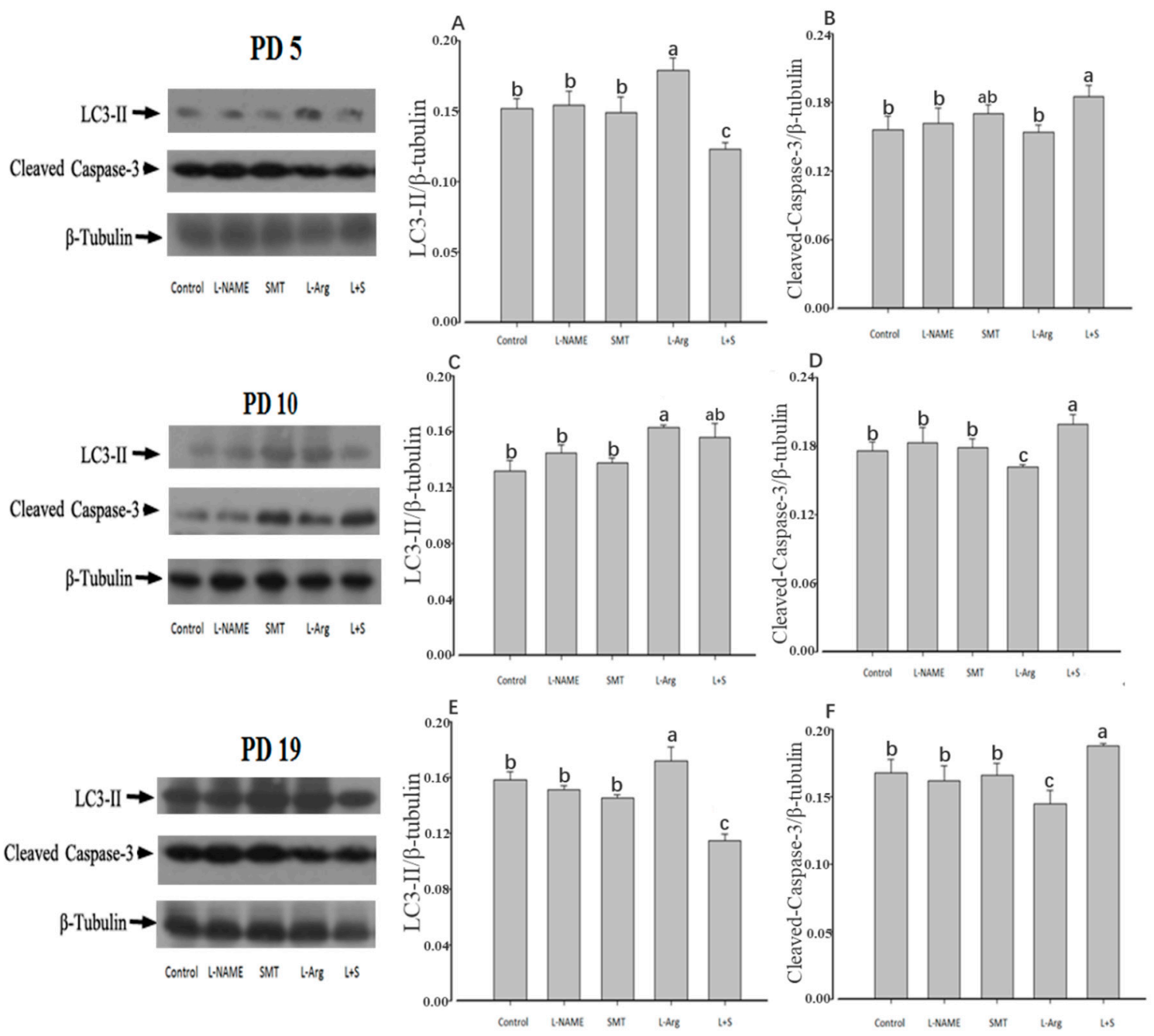

Figure 6. Effect of NOS inhibitors and substrate on ovarian expression of LC3-II $(\mathbf{A}, \mathbf{C}, \mathbf{E})$ and cleaved-Caspase-3 (B,D,F) in neonatal and immature rats. Animals in the control, L-NAME, SMT, L-Arg, or L + S (L-NAME plus SMT) groups were subcutaneously hypodermically injected with PBS, L-NG-Nitroarginine Methyl Ester (40 mg/kg), S-Methylisothiourea (10 mg/kg), L-NG-Nitroarginine Methyl Ester (40 mg/kg) and S-Methylisothiourea (10 mg/kg), or L-arginine (50 mg/kg) for five (PD5), 10 (PD10) and 19 days (PD19) from the first day of birth (PD1). As an internal control, $\beta$-tubulin was used, wherein the signal intensity was plotted as the ratio of target protein to $\beta$-tubulin. Bars with different letters denote significant differences $(p<0.05)$.

\section{Discussion}

The complexity of ovarian internal factors regulating follicular development and oocyte maturity requires further investigation [48]. To address this, NOS inhibition models were established via injection of L-NAME $(40 \mathrm{mg} / \mathrm{kg})$ and SMT $(10 \mathrm{mg} / \mathrm{kg})$ in vivo as selective inhibitors of eNOS and iNOS, respectively. The results revealed that follicular morphology and NOS activity were not significantly impaired by a single NOS inhibitor injection of L-NAME or SMT; the injection concentration of L-NAME or SMT may have been too low to affect the activity of selective eNOS or iNOS [10], and a higher level of inhibitor could induce death. Therefore, L-NAME plus SMT might contribute to synergistic inhibition, and we found that it significantly decreased the NOS activity and NO content in neonatal and immature rats. Furthermore, L-Arg promoted NO generation and induced advanced follicular development. This is consistent with the finding that the ratio between NO synthesis boosters and inhibitors is higher in ewes carrying multiple fetuses [49]. 
A previous study reported that sGC, a cGMP synthesizing enzyme, is mainly expressed in the granulosa cells of primordial follicles and preantral follicles, indicating possible associations between the cGMP signal transduction pathway with the initiation of follicle growth [50]. The fact that FoxO3 is over-phosphorylated with PI3K and ATK activation induced by PTEN-deficient oocytes indicates the possibility that the $\mathrm{PI} 3 \mathrm{~K} / \mathrm{FoxO} 3$ pathway is the key factor regulating the activation of primordial follicles [25,27]. During the migration of endothelial cells, NO downregulates peroxisome proliferator by activating the PI3K/AKT pathway and inactivating FoxO3a protein, thereby inhibiting and downregulating PGC-1 $\alpha$ [31]. The above mechanisms may explain our observation that the percentage of antral follicle is significantly elevated or decreased after injection of L-Arg or L $+\mathrm{S}$, respectively. Consistently, NOS inhibition resulted in the suppression of NO synthesis and antral follicle development [8]. However, the NOS substrate and inhibitor has different influence across ages, and injection of L-Arg significantly increased or decreased the secondary follicle (SF) percentage on PD10 or PD19 respectively, since the NOS substrate or inhibitor might contribute to different functions of the ovary at different stages. For example, NO is produced by iNOS only in immature follicles at earlier stages in rats [18].

Furthermore, previous studies have found that the NO/cGMP pathway participated in the follicle development of rats and porcine animals $[34,35]$. Therefore, the current investigation was designed to reveal the relationship between the NO/cGMP and PI3K pathways during follicular development in neonatal rats, particularly in the immature period from birth to puberty. The activity of FoxOs is tightly regulated by posttranslational modification, including phosphorylation, acetylation, and ubiquitylation [51]. The p-FoxO3a proteins are positioned in the oocyte nucleolus of primordial and primary follicles, and transfer to the cytoplasts in secondary and mature follicles, thus possibly initiating follicular development [52]. Our study showed that the key proteins of the PI3K/AKT/FoxO3a pathway, including PTEN, AKT, and FoxO3a, were highly expressed in the ovary on PD5, PD10, and PD19. This finding is consistent with the expression of key proteins in oocyte and granulosa cells in adult animals, where p-AKT is expressed in adult porcine ovarian granulosa cells of medium follicles associated with autophagy [53], and follicle loss has been ascribed to the activation of the PTEN/PI3K/AKT pathway in adult female mice [54].

As reported, NOS/cGMP activated the PI3K/AKT pathway [55], which is involved in chemotherapy-induced follicular activation and responds to fragmentation [56]. In addition, the NOS/cGMP pathway is related to the angiotensin (HIF-1) in endothelial cells [57]. Therefore, NOS/cGMP is engaged via numerous routes in the PI3K/AKT pathway, through it remains unclear whether it can further activate FoxO3a, especially during ovary development in female neonatal rats. Compared with the control group on PD19, Western blotting analysis showed that the NOS substrate induced downregulation of PTEN and upregulation of $\mathrm{p}$-AKT and p-FoxO3a, while the combined NOS inhibitors upregulated PTEN and downregulated p-AKT and p-FoxO3a. There is the possibility that NOS might activate the PI3K/AKT/FoxO3a pathway via downregulation of PTEN and upregulation of $\mathrm{p}$-AKT and p-FoxO3a during follicular development in immature rats. However, how NOS mediates the PI3K/AKT/FoxO3a pathway through cGMP and regulates follicular development requires further investigation.

This study showed that the apoptosis-marker protein of cleaved Caspase3 and the autophagia-marker protein of LC3-II were highly expressed in the ovary on PD5, PD10, and PD19, which was consistent with previous studies [58]. The participation of apoptosis and autophagia in follicular development was contributed to by oocyte atresia $[59,60]$. Furthermore, NO has been proven to function in cell autophagia and apoptosis [61-63], wherein high-content NO could accelerate oocyte atresia by producing excessive superoxide or inducing apoptosis $[64,65]$. The current study confirmed the role of NOS in the ovarian development of neonatal and immature female rats via cell autophagia and apoptosis, with upregulation of LC3-II and downregulation of cleaved Caspase-3 of L-Arg injected rats on PD19 along with elevated activity of NOS and content of NO in the ovary, while the injection of L-NAME plus SMT showed the opposite regulation of LC3-II and cleaved Caspase-3 in the ovary. 


\section{Conclusions}

In summary, daily exposure to NOS subcutaneous administration in female neonatal and immature rats proficiently contributed to $\mathrm{NO}$ generation and follicular development for 19 consecutive days. The NOS substrate contribution induced downregulation of PTEN and upregulation of p-AKT and p-FoxO3a, which are associated with upregulation of LC3-II and downregulation of cleaved Caspase-3 during follicular autophagy and apoptosis in neonatal and immature female rats respectively. This study provides a novel perspective in understanding progressive follicular development using NOS substrates. These insights may serve as a reference for further investigation of the mechanism involved in the progressive follicular development of antral follicles in the ovaries.

Author Contributions: Project administration, investigation, writing—original draft preparation, J.L.; formal analysis, investigation, writing-original draft preparation, W.Z.; formal analysis, S.Z.; project administration, writing-review and editing, F.S. All authors have read and agreed to the published version of the manuscript.

Funding: This research was funded by the National Natural Science Foundation of China, grant number 31572403.

Acknowledgments: We would like to express our gratitude to Enayatullah Hamdard for reading the original manuscript and offering valuable suggestions.

Conflicts of Interest: The authors declare no conflicts of interest.

\section{References}

1. Maksoud, M.J.E.; Tellios, V.; Xiang, Y.Y.; Lu, W.Y. Nitric oxide signaling inhibits microglia proliferation by activation of protein kinase-G. Nitric. Oxide. 2019, 94, 125-134. [CrossRef] [PubMed]

2. Stuehr, D.J.; Vasquez-Vivar, J. Nitric oxide synthases-from genes to function. Nitric. Oxide. 2017, 63, 29. [CrossRef] [PubMed]

3. Alderton, W.K.; Cooper, C.E.; Knowles, R.G. Nitric oxide synthases: Structure, function and inhibition. Biochem. J. 2001, 357 Pt 3, 593-615. [CrossRef]

4. Förstermann, U.; Sessa, W.C. Nitric oxide synthases: Regulation and function. Eur. Heart J. 2012, 33, 829-837. [CrossRef] [PubMed]

5. Olson, L.M.; Jones-Burton, C.M.; Jablonka-Shariff, A. Nitric oxide decreases estradiol synthesis of rat luteinized ovarian cells: Possible role for nitric oxide in functional luteal regression. Endocrinology 1996, 137, 3531-3539. [CrossRef]

6. Xu, K.; Tian, Y.; Weng, X.; Hu, X.; Heng, D.; Xia, G.; Zhang, C. Effect of thyroid dysfunction on NOS expression in the female rat. Cell Tissue Res. 2019. [CrossRef]

7. Becerril, S.; Rodríguez, A.; Catalán, V.; Ramírez, B.; Unamuno, X.; Portincasa, P.; Gómez-Ambrosi, J.; Frühbeck, G. Functional Relationship between Leptin and Nitric Oxide in Metabolism. Nutrients 2019, 11, 2129. [CrossRef]

8. Zheng, K.; Sulieman, F.J.; Li, J.; Wei, Q.; Xu, M.; Shi, F. Nitric oxide and thyroid hormone receptor alpha 1 contribute to ovarian follicular development in immature hyper- and hypo-thyroid rats. Reprod. Biol. 2015, 15, 27-33. [CrossRef]

9. Grazul-Bilska, A.T.; Bass, C.S.; Kaminski, S.L.; Ebel, K.K.; Leke, E.; Thammasiri, J.; Kraisoon, A.; Navanukraw, C.; Holst, M.; Shelton, M.; et al. Effects of plane of nutrition and arginine on ovarian follicles in non-pregnant sheep: Cell proliferation, and expression of endothelial nitric oxide and its receptor. Acta. Histochem. 2019, 121, 189-197. [CrossRef]

10. Basini, G.; Grasselli, F. Nitric oxide in follicle development and oocyte competence. Reproduction 2015, 150, R1-R9. [CrossRef]

11. Grazul-Bilska, A.T.; Navanukraw, C.; Johnson, M.L.; Arnold, D.A.; Reynolds, L.P.; Redmer, D.A. Expression of endothelial nitric oxide synthase in the ovine ovary throughout the estrous cycle. Reproduction 2006, 132, 579-587. [CrossRef] [PubMed]

12. Delsouc, M.B.; Della Vedova, M.C.; Ramírez, D.; Delgado, S.M.; Casais, M. The production of nitric oxide in the coeliac ganglion modulates the effect of cholinergic neurotransmission on the rat ovary during the preovulatory period. Nitric. Oxide. 2018, 75, 85-94. [CrossRef] 
13. Singh, V.K.; Lal, B. Nitric oxide (NO) stimulates steroidogenesis and folliculogenesis in fish. Reproduction 2017, 153, 133-146. [CrossRef] [PubMed]

14. Yang, X.; Tan, J.; Xu, X.; Yang, H.; Wu, F.; Xu, B.; Liu, W.; Shi, P.; Xu, Z.; Deng, Y. Prepubertal overexposure to manganese induce precocious puberty through GABAA receptor/nitric oxide pathway in immature female rats. Ecotoxicol. Environ. Saf. 2019, 188, 109898. [CrossRef] [PubMed]

15. Krishna, M.B.; Joseph, A.; Thomas, P.L.; Dsilva, B.; Pillai, S.M.; Laloraya, M. Impaired arginine metabolism coupled to a defective redox conduit contributes to low plasma nitric oxide in polycystic ovary syndrome. Cell. Physiol. Biochem. 2017, 43, 1880-1892. [CrossRef] [PubMed]

16. Pallares, P.; Garcia-Fernandez, R.A.; Criado, L.M.; Letelier, C.A.; Esteban, D.; Fernandez-Toro, J.M.; Flores, J.M.; Gonzalez-Bulnes, A. Disruption of the endothelial nitric oxide synthase gene affects ovulation, fertilization and early embryo survival in a knockout mouse model. Reproduction 2008, 136, 573-579. [CrossRef]

17. Jablonka-Shariff, A.; Ravi, S.; Beltsos, A.N.; Murphy, L.L.; Olson, L.M. Abnormal estrous cyclicity after disruption of endothelial and inducible nitric oxide synthase in mice. Biol. Reprod. 1999, 61, 171-177. [CrossRef]

18. Moonmanee, T.; Navanukraw, C.; Uriyapongson, S.; Kraisoon, A.; Aiumlamai, S.; Guntaprom, S.; Rittirod, T.; Borowicz, P.P.; Redmer, D.A. Relationships among vasculature, mitotic activity, and endothelial nitric oxide synthase (eNOS) in bovine antral follicles of the first follicular wave. Domest. Anim. Endocrinol. 2013, 45, 11-21. [CrossRef]

19. Matsumi, H.; Yano, T.; Osuga, Y.; Kugu, K.; Tang, X.; Xu, J.P.; Yano, N.; Kurashima, Y.; Ogura, T.; Tsutsumi, O.; et al. Regulation of nitric oxide synthase to promote cytostasis in ovarian follicular development. Biol. Reprod. 2000, 63, 141-146. [CrossRef]

20. Tsutsui, M.; Shimokawa, H.; Morishita, T.; Nakashima, Y.; Yanagihara, N. Development of genetically engineered mice lacking all three nitric oxide synthases. Pharmacol. Sci. 2006, 102, 147-154. [CrossRef]

21. Cantley, L.C. The phosphoinositide 3-kinase pathway. Science 2002, 296, 1655-1657. [CrossRef] [PubMed]

22. Cully, M.; You, H.; Levine, A.J.; Mak, T.W. Beyond PTEN mutations: The PI3K pathway as an integrator of multiple inputs during tumorigenesis. Nat. Rev. Cancer 2006, 6, 184-192. [CrossRef]

23. Tran, H.; Brunet, A.; Griffith, E.C.; Greenberg, M.E. The many forks in FOXO's road. Sci. STKE 2003, 172, RE5. [CrossRef] [PubMed]

24. Jia, Y.; Mo, S.J.; Feng, Q.Q.; Zhan, M.L.; Ouyang, L.S.; Chen, J.C.; Ma, Y.X.; Wu, J.J.; Lei, W.L. EPO-dependent activation of PI3K/Akt/Foxo3a signalling mediates neuroprotection in in vitro and in vivo models of Parkinson's disease. J. Mol. Neurosci. 2014, 53, 117-124. [CrossRef] [PubMed]

25. Castrillon, D.H.; Miao, L.; Kollipara, R.; Horner, J.W.; DePinho, R.A. Suppression of ovarian follicle activation in mice by the transcription factor Foxo3a. Science 2003, 301, 215-218. [CrossRef] [PubMed]

26. Liu, K.; Rajareddy, S.; Liu, L.; Jagarlamudi, K.; Boman, K.; Selstam, G.; Reddy, P. Control of mammalian oocyte growth and early follicular development by the oocyte PI3 kinase pathway: New roles for an old timer. Dev. Biol. 2006, 299, 1-11. [CrossRef] [PubMed]

27. John, G.B.; Gallardo, T.D.; Shirley, L.J.; Castrillon, D.H. Foxo3 is a PI3Kdependent molecular switch controlling the initiation of oocyte growth. Dev. Biol. 2008, 321, 197-204. [CrossRef]

28. Hou, Y.; Sun, G.; Jiang, X.; Zhu, Z.; Yang, J. Nuclear forkhead box O3a accumulation contributing to the proliferative suppression in liver cancer cells by PI3K/Akt signaling pathway. J. Cancer Res. Ther. 2018, 14, 1124.

29. Wu, H.C.; Zhang, J.W.; Sun, Z.G.; Xiang, S.; Qiao, Y.; Lian, F. Effects of Electroacupuncture on Expression of PI3K/Akt/Foxo3a in Granulosa Cells from Women with Shen (Kidney) Deficiency Syndrome Undergoing in vitro Fertilization-Embryo Transfer. Chin. J. Integr. Med. 2019, 25, 252-258. [CrossRef]

30. Wang, Z.; Li, Y.; Wang, Y.; Zhao, K.; Chi, Y.; Wang, B. Pyrroloquinoline quinine protects HK-2 cells against high glucose-induced oxidative stress and apoptosis through Sirt3 and PI3K/Akt/FoxO3a signaling pathway. Biochem. Biophys. Res. Commun. 2019, 508, 398-404. [CrossRef]

31. Borniquel, S.; García-Quintáns, N.; Valle, I.; Olmos, Y.; Wild, B.; Martínez-Granero, F.; Soria, E.; Lamas, S.; Monsalve, M. Inactivation of Foxo3a and subsequent downregulation of PGC-1 alpha mediate nitric oxide-induced endothelial cell migration. Mol. Cell. Biol. 2010, 30, 4035-4044. [CrossRef] [PubMed]

32. Zheng, W.; Nagaraju, G.; Liu, Z.; Liu, K. Functional roles of the phosphatidylinositol 3-kinases (PI3Ks) signaling in the mammalian ovary. Mol. Cell. Endocrinol. 2012, 356, 24-30. [CrossRef] [PubMed] 
33. Wang, L.; Ni, Z.; Liu, Y.; Ji, S.; Jin, F.; Jiang, K.; Ma, J.; Ren, C.; Zhang, H.; Hu, Z.; et al. Hyperactivated mTORC1 downregulation of FOXO3a/PDGFR $\alpha /$ AKT cascade restrains tuberous sclerosis complex-associated tumor development. Oncotarget 2017, 8, 54858-54872.

34. Ding, W.; Zhang, W.; Hui, F.M.; Zhang, Y.H.; Zhang, F.F.; Li, X.M.; Shi, F.X. Cell-specific expression and immunolocalization of nitric oxide synthase isoforms and soluble guanylyl cyclase $\alpha 1$ and $\beta 1$ subunits in the ovary of fetal, neonatal and immature pigs. Anim. Reprod. Sci. 2012, 131, 172-180. [CrossRef]

35. Zhang, W.; Wei, Q.W.; Wang, Z.C.; Ding, W.; Wang, W.; Shi, F.X. Cell-specific expression and immunolocalization of nitric oxide synthase isoforms and the related nitric oxide/cyclic GMP signaling pathway in the ovaries of neonatal and immature rats. J. Zhejiang Univ. Sci. B 2011, 12, 55-64. [CrossRef]

36. Castardo-de-Paula, J.C.; de Campos, B.H.; Amorim, E.D.T.; da Silva, R.V.; de Farias, C.C.; Higachi, L.; Pinge-Filho, P.; Barbosa, D.S.; Martins-Pinge, M.C. Cardiovascular risk and the effect of nitric oxide synthase inhibition in female rats: The role of estrogen. Exp. Gerontol. 2017, 97, 38-48. [CrossRef]

37. Hasarmeh, M.; Itzik, A.; Weidenfeld, J.; Ovadia, H. Modulation of Hyperosmotic and Immune-Induced Disruption of the Blood-Brain Barrier by the Nitric Oxide System. Neuroimmunomodulation 2016, 23, 1-7. [CrossRef]

38. Hallemeesch, M.M.; Cobben, D.C.; Soeters, P.B.; Deutz, N.E. Differential effects of selective and non-selective NOS inhibition on renal arginine and protein metabolism during endotoxemia in rats. Clin. Nutr. 2002, 21, 111-117. [CrossRef]

39. Vrankova, S.; Zemancikova, A.; Torok, J.; Pechanova, O. Effect of low dose L-NAME pretreatment on nitric oxide/reactive oxygen species balance and vasoactivity in L-NAME/salt-induced hypertensive rats. J. Physiol. Pharmacol. 2019, 70. [CrossRef]

40. Nath, P.; Mukherjee, U.; Biswas, S.; Pal, S.; Das, S.; Ghosh, S.; Samanta, A.; Maitra, S. Expression of nitric oxide synthase (NOS) in Anabas testudineus ovary and participation of nitric oxide-cyclic GMP cascade in maintenance of meiotic arrest. Mol. Cell. Endocrinol. 2019, 496, 110544. [CrossRef]

41. Bulbul, T.; Akosman, M.S.; Yilmaz, O.; Ulutas, E.; Bulbul, A. Supplementary dietary nitric oxide donor (sodium nitroprusside) or inhibitor (NG-nitro-L-arginine methyl ester) depressed growth performance and ovarian primordial and primary follicles in Japanese quail (Coturnix coturnix japonica) in a dose-dependent manner. Br. Poult. Sci. 2015, 56, 113-120. [PubMed]

42. Witlin, A.G.; Gangula, P.R.; Thompson, M.L.; Yallampalli, C. Growth and fertility rates in the offspring of pregnant rats treated with L-omega nitro-L-arginine methyl ester (L-NAME), a nitric oxide inhibitor. Am. J. Obstet. Gynecol. 2002, 186, 89-93. [CrossRef] [PubMed]

43. Bednov, A.; Espinoza, J.; Betancourt, A.; Vedernikov, Y.; Belfort, M.; Yallampalli, C. L-arginine prevents hypoxia-induced vasoconstriction in dual-perfused human placental cotyledons. Placenta 2015, 36, 1254-1259. [CrossRef] [PubMed]

44. Differ, C.; Klatte-Schulz, F.; Bormann, N.; Minkwitz, S.; Knaus, P.; Wildemann, B. Is NO the Answer? The Nitric Oxide Pathway Can Support Bone Morphogenetic Protein 2 Mediated Signaling. Cells 2019, 8, 1273. [CrossRef]

45. Zhang, H.; Sun, H.; Peng, A.; Guo, S.; Wang, M.; Loor, J.J.; Wang, H. N-carbamylglutamate and l-arginine promote intestinal function in suckling lambs with intrauterine growth restriction by regulating antioxidant capacity via a nitric oxide-dependent pathway. Food Funct. 2019, 10, 6374-6384. [CrossRef]

46. Vitt, U.A.; McGee, E.A.; Hayashi, M.; Hsueh, A.J. In vivo treatment with GDF-9 stimulates primordial and primary follicle progression and theca cell marker CYP17 in ovaries of immature rats. Endocrinology 2000, 141, 3814-3820. [CrossRef]

47. Wei, Q.; Korejo, N.A.; Jiang, J.; Xu, M.; Zheng, K.; Mao, D.; Shi, F. Mitigation of stress from gastric mucosal injuries by mulberry extract may occur via nitric oxide synthase signaling in mice. Tissue Cell 2018, 54, 59-64. [CrossRef]

48. Sheshpari, S.; Shahnazi, M.; Mobarak, H.; Ahmadian, S.; Bedate, A.M.; Nariman-Saleh-Fam, Z.; Nouri, M.; Rahbarghazi, R.; Mahdipour, M. Ovarian function and reproductive outcome after ovarian tissue transplantation: A systematic review. J. Transl. Med. 2019, 17, 396. [CrossRef]

49. Berlinguer, F.; Porcu, C.; Molle, G.; Cabiddu, A.; Dattena, M.; Gallus, M.; Pasciu, V.; Succu, S.; Sotgiu, F.D.; Paliogiannis, P.; et al. Circulating concentrations of key regulators of nitric oxide production in undernourished sheep carrying single and multiple fetuses. Animals 2020, 10, 65. [CrossRef] 
50. Shi, F.; Stewart, R.L.; Pere, E.; Chen, J.Y.; LaPolt, P.S. Cell-specific expression and regulation of soluble guanylyl cyclase alpha and beta subunit in the rat ovary. Bio Reprod. 2004, 70, 1552-1561. [CrossRef]

51. Wang, Y.; Zhou, Y.; Graves, D.T. FOXO transcription factors: Their clinical significance and regulation. Biomed. Res. Int. 2014, 2014, 925350. [CrossRef] [PubMed]

52. Yamamura, Y.; Lee, W.L.; Inoue, K.; Ida, H.; Ito, Y. RUNX3 cooperates with FoxO3a to induce apoptosis in gastric cancer cells. J. Biol. Chem. 2006, 281, 5267-5276. [CrossRef] [PubMed]

53. Zheng, Y.; Ma, L.; Liu, N.; Tang, X.; Guo, S.; Zhang, B.; Jiang, Z. Autophagy and apoptosis of porcine ovarian granulosa cells during follicular development. Animals 2019, 9, 1111. [CrossRef] [PubMed]

54. Xia, H.; Zhang, R.; Guan, H.; Zhang, W. Follicle loss and PTEN/PI3K/mTOR signaling pathway activated in LepR-mutated mice. Gynecol. Endocrinol. 2019, 35, 44-48. [CrossRef] [PubMed]

55. Ha, K.S.; Kim, K.M.; Kwon, Y.G.; Bai, S.K.; Nam, W.D.; Yoo, Y.M.; Kim, P.K.; Chung, H.T.; Billiar, T.R.; Kim, Y.M. Nitric oxide prevents 6-hydroxydopamine-induced apoptosis in PC12 cells through cGMP-dependent PI3 kinase/Akt activation. FASEB J. 2003, 17, 1036-1347. [CrossRef] [PubMed]

56. Devos, M.; Grosbois, J.; Demeestere, I. Interaction between PI3K/AKT and Hippo pathways during in vitro follicular activation and response to fragmentation and chemotherapy exposure using a mouse immature ovary model. Biol. Reprod. 2019, ioz215. [CrossRef]

57. Carver, D.J.; Gaston, B.; Deronde, K.; Palmer, L.A. Akt-Mediated Activation of HIF-1 in Pulmonary Vascular Endothelial Cells by S-Nitrosoglutathione. Am. J. Respir. Cell Mol. Biol. 2007, 37, 255-263. [CrossRef]

58. Choi, J.Y.; Jo, M.W.; Lee, E.Y.; Yoon, B.K.; Choi, D.S. The role of autophagy in follicular development and atresia in rat granulosa cells. Fertil. Steril. 2010, 93, 2532-2537. [CrossRef]

59. Rosselli, M.; Keller, P.J.; Dubey, R.K. Role of nitric oxide in the biology, physiology and pathophysiology of reproduction. Hum. Reprod. Update 1998, 4, 3-24. [CrossRef]

60. Kim, Y.M.; Bombeck, C.A.; Billiar, T.R. Nitric Oxide as a bifunctional regulator of apoptosis. Circ. Res. 1999, 84, 253-256. [CrossRef]

61. Sarkar, S.; Korolchuk, V.I.; Renna, M.; Imarisio, S.; Fleming, A.; Williams, A.; Garcia-Arencibia, M.; Rose, C.; Luo, S.; Underwood, B.R.; et al. Complex inhibitory effects of nitric oxide on autophagy. Mol. Cell 2011, 43, 19-32. [CrossRef] [PubMed]

62. Rabkin, S.W.; Klassen, S.S. Nitric oxide differentially regulates the gene expression of caspase genes but not some autophagic genes. Nitric Oxide 2007, 16, 339-347. [CrossRef] [PubMed]

63. Rabkin, S.W. Nitric oxide-induced cell death in the heart: The role of autophagy. Autophagy 2007, 3, 347-349. [CrossRef] [PubMed]

64. $\mathrm{Xu}, \mathrm{M}$.; Zhang, H.L. Death and survival of neuronal and astrocytic cells in ischemic brain injury: A role of autophagy. Acta Pharmacol. Sin. 2011, 32, 1089-1099. [CrossRef]

65. Boya, P.; González-Polo, R.A.; Casares, N.; Perfettini, J.L.; Dessen, P.; Larochette, N.; Métivier, D.; Meley, D.; Souquere, S.; Yoshimori, T.; et al. Inhibition of macroautophagy triggers apoptosis. Mol. Cell. Biol. 2005, 25, 1025-1040. [CrossRef]

(C) 2020 by the authors. Licensee MDPI, Basel, Switzerland. This article is an open access article distributed under the terms and conditions of the Creative Commons Attribution (CC BY) license (http://creativecommons.org/licenses/by/4.0/). 